\title{
Kinetics of the Conversion of Glucose to Gluconic Acid by Pseudomonas ovalis
}

\author{
DANIEL NEWELL BULL, Research and Development Department, \\ Continental Oil Company and LLOYD L. KEMPE, Department of \\ Chemical and Metallurgical Engineering, University of Michigan
}

\begin{abstract}
Summary
The concept of a "critical oxygen concentration" is conventionally considered to hold for the submerged aerobic fermentation of glucose to gluconic acid. Above the critical level the fermentation rate is supposedly independent of oxygen concentration. In this work it is shown that, at a given agitation rate, the fermentation is independent of dissolved oxygen when above the critical. However, an increase in the agitation rate results in an increase in the fermentation rate. This increase was shown to be accompanied by an increase in the gluconolactone concentration in the broth. Gluconolactone, an intermediate in the reaction pathway, is hydrolyzed nonenzymatically to gluconic acid. Evidence is presented to suggest that the increased gas-liquid interfacial area brought about by increased agitation causes an increased net rate of lactone formation. This in turn results in an increased rate of hydrolysis of the lactone to gluconic acid. A model is presented hypothesizing that negatively charged cells adsorb at the gas-liquid interface. These cells attract hydrogen ions, causing a lowering of the $\mathrm{pH}$ in the film around the bubbles. It is this lowered $\mathrm{pH}$ which is considered to bring about increased fermentation rates when the interfacial area is increased. Supporting evidence is presented.
\end{abstract}

\section{INTRODUCTION}

Fermentor systems for carrying out submerged, aerobic industrial fermentations are usually sparged, agitated gas-liquid contactors. Oxygen transfer with simultaneous chemical reaction is facilitated by agitation or power input. Many engineering studies of such systems have been carried out. The ultimate objective of these studies is to determine the level of aeration and agitation necessary to ensure maximum productivity of the desired fermentation product at least cost. $^{11}$

(C) 1970 by John Wiley \& Sons, Inc. 
Most commonly, the rates of oxygen absorption measured or estimated in such studies are interpreted in physical terms. Mass transfer coefficients are reported with little or no attention being paid to the effect of the metabolic reactions taking place as a result of the absorption. Recently, Hsieh, Silver and Mateles ${ }^{15}$ described the use of glucose oxidase preparations to measure oxygen transfer rates. The method was used only when the dissolved oxygen concentration was less than the apparent Michaelis constant for oxygen. $\mathrm{TsaO}^{29}$ used a similar system to measure oxygen absorption with simultaneous biochemical reaction. These studies were concerned with homogeneous catalysis. In an actual fermentation, oxygen is absorbed into the fermentation medium, and then passes to the cells, where it is metabolized as a terminal electron acceptor. Since some of the cells will be found in the liquid film around the bubbles, a significant portion of the total oxygen transferred could be metabolized in this film. Astarita ${ }^{2}$ has outlined a procedure for estimating the magnitude of these effects in a simple, clear manner. He defined the average life, $t_{D}$, of surface elements in the gas-liquid interface by:

$$
t_{D} \equiv D_{L} /\left(k_{L}{ }^{0}\right)^{2}
$$

Astarita further defined the "reaction time," $t_{r}$, as

$$
t_{r} \equiv\left(C_{s}-C_{e}\right) / r\left(C_{s}-C_{e}\right)
$$

According to the scheme of Astarita, $t_{D}$ is the average time available for reaction in surface elements before they are returned to the bulk liquid, and $t_{r}$ is the minimum time necessary for reaction to take place to a significant extent. If $t_{D} \ll t_{r}$, that is ,if

$$
D_{L} /\left(k_{L}^{0}\right)^{2} \ll\left[\left(C_{s}-C_{e}\right) / r\left(C_{s}-C_{e}\right)\right]
$$

then there will not be a significant amount of reaction taking place in a surface element during the life of that particular element, and the absorption coefficient will not be affected by the chemical reaction, that is

$$
k_{L}=k_{L}^{0}
$$

This does not mean that the absorption rate will be unaffected by the chemical reaction. In fact if eq. (3) is fulfilled, and if

$$
r\left(C_{s}-C_{e}\right) \ll k_{L}^{0} a\left(C_{s}-C_{e}\right)
$$


then it is true that, for a batch absorber in the pseudo-steady state, the total absorption rate is, according to Astarita: $(i)$ independent of interface area; (ii) independent of $k_{L}{ }^{0}$; (iii) proportional to $r$; and (iv) influenced by the overall driving force $C_{s}-C$, except for zeroorder reaction.

The absorption rate per unit volume of liquid for a zero order reaction will be given by

$$
q=r\left(C_{s}-C_{e}\right)=k
$$

Moreover, as related by Astarita, any absorber for which the bulk oxygen concentration is significantly higher than the chemical equilibrium concentration, $C_{e}$, must satisfy eqs. (3) and (5), and hence eq. (6) also.

The concept of a "critical" oxygen concentration in fermentations, as developed by Winzler, ${ }^{32}$ is related to this phenomenon. According to this concept when the bulk oxygen level is above the "critical," the oxygen utilization rate is independent of the dissolved oxygen concentration. Winzler attributed the effect to saturation of the enzyme system. "Critical" oxygen concentrations have been reported in the literature for a number of organisms and substrates. $1,10,12,18,24,27,28,32$ Fermentations involving these and similar organisms which operate at dissolved oxygen concentrations above the critical can be considered as carrying out a zero order reaction with respect to the absorbed component oxygen.

Thus the rate of any fermentation for which a "critical" concentration exists will be independent of the absorption coefficient, $k_{L}{ }^{0}$, the gas-liquid interfacial area, $a$, and the absorption driving force $\left(C_{s}-C\right)$, provided the bulk oxygen concentration is above the "critical" level. The fermentation rate will depend solely on the reaction kinetics of oxygen uptake.

Physical absorption coefficients for fermentor systems are of great interest, but they are not the primary variable. Rather, the controlling factor in systems of the type under discussion is reaction kinetics, or, more precisely, enzyme kinetics. Furthermore, in the absence of any other effects, improvements in the absorption coefficient in such systems are of no advantage whatsoever.

In spite of this, a considerable body of data is being accumulated in the literature describing fermentations in which increase rates can be obtained under certain conditions even when the dissolved oxygen 
level is above the critical. ${ }^{1,4,5,25,31}$ Few explanations for such effects have been advanced. Phillips, Sallans, and Spencer ${ }^{23}$ proposed that oxygen molecules adsorb at the gas-liquid interface, leading to an increase in the oxygen absorption rate in fermentations. Such a mechanism should make no difference when the dissolved oxygen concentration is above the "critical." Bartholomew, Karow, Sfat, and Wilhelm ${ }^{3}$ proposed a shortened path for oxygen transfer for cells at the gas-liquid interface. Bennett and Kempe ${ }^{5}$ suggested such a path as a mechanism for increased oxygen transfer in the gluconic acid fermentation of Pseudomanas ovalis. Tsao ${ }^{29}$ has suggested a similar mechanism in the homogeneous oxidation of glucose to gluconic acid using fungal glucose oxidase preparation. The heterogeneous gluconic acid fermentation of Pseudomonas ovalis is interesting in that in the pseudo-steady state, the rate of oxygen absorption is proportional to the rate of production of gluconic acid, according to the overall reaction

$$
\text { D-glucose }+\frac{1}{2} \mathrm{O}_{2} \rightarrow \text { D-gluconic acid }
$$

The conversion is quantitative for the $P$. ovalis system, with no side reactions. ${ }^{5,21,30}$ In a nitrogen free medium, in which there is no growth of cells, the rate of gluconic acid production is directly proportional to the oxygen uptake rate in the pseudo-steady state.

Aiba, Hara, and Someya ${ }^{1}$ have reported that a critical oxygen concentration exists for the gluconic acid fermentation of $P$. ovalis. However, Tsao and $\mathrm{Kempe}^{30}$ and Bennett and Kempe ${ }^{5}$ found that oxygen uptake could be increased for this fermentation by increasing the rate of agitation of the broth, even when the dissolved oxygen was above the "critical."

According to the concepts outlined here, such an increase could not be due to an improvement in the transfer coefficient. The effects must, on the other hand, be due to changes in the enzyme kinetics due to changes in the agitation rate. Experiments were designed with this assumption in mind.

\section{EQUIPMENT, MATERIALS, AND METHODS}

A strain of Pseudomonas ovalis, NRRL B-8S, obtained from the Northern Utilization Research and Development Branch, United BIOTECHNOLOGY AND BIOENGINEERING, VOL. XII, ISSUE 2 
States Department of Agriculture, Peoria, Illinois, was used for this study.

\section{Equipment}

A 5 liter New Brunswick Scientific Company fermentor of conventional design was employed. The fermentor was equipped with a $\mathrm{pH}$ recorder-controller and a dissolved oxygen probe. The fermentor was immersed in a water bath for temperature control. Details of the equipment are given in Reference 6 .

\section{Experimental Procedure}

The culture was maintained in a glucose-yeast extract medium at $30^{\circ} \mathrm{C}$. A small amount of calcium carbonate was added to the medium as a buffer. Transfers were made every two days. For an experiment, one liter of sterile medium in a 2 liter Erlenmeyer flask was inoculated with ten $\mathrm{ml}$ of a $24 \mathrm{hr}$-old culture. The culture was then incubated for 16 to $18 \mathrm{hr}$ at $30^{\circ} \mathrm{C}$ on a rotary shaker. At this point the cells were in about the middle of the stationary phase of growth. Next the $\mathrm{pH}$ was adjusted from about 4.3 to 7.0 with $4 \mathrm{~N}$ sodium hydroxide. The cells were then aerated vigorously for 30 min with air blown through an Aloxite sparger.

The cells were next centrifuged from the broth at $1060 \times \mathrm{g}$ for $30 \mathrm{~min}$. The supernatant was decanted, and the cell packs were drained and resuspended in a nitrogen-free medium of the following composition, designated Medium B:

$\begin{array}{ll}\text { Glucose } & 50 \mathrm{~g} \\ \mathrm{~K}_{2} \mathrm{HPO} & 0.9 \mathrm{~g} \\ \mathrm{KH}_{2} \mathrm{PO} & 0.6 \mathrm{~g} \\ \text { Polyglycol P-2000 } & 4 \text { drops (Dow Chemical Co., Midland, Michigan) } \\ \text { Silicone Antifoam B } & 1 \text { drop (Dow-Corning Corp., Midland, Michigan) } \\ \text { Distilled water } & 2.0 \text { liters }\end{array}$

This medium was not autoclaved. Cell concentration was adjusted to 100 units on a Klett-Summerson photocolorimeter at $420 \mathrm{~m} \mu$. Viable cell count was about $10^{7}$ cells per ml.

Two liters of this supension were charged to the fermentor, which was maintained at $25 \pm 0.2^{\circ} \mathrm{C}$. Air was sparged through the medium 
at 2.0 liters per minute, and the $\mathrm{pH}$ was controlled at $7.0 \pm 0.05 \mathrm{pH}$ units unless otherwise noted. The agitation rate was variable.

Acid production was measured from the rate of addition of $0.5 \mathrm{~N}$ sodium hydroxide necessary to maintain a constant $\mathrm{pH}$. The caustic was standardized by titration against potassium acid phthalate, with a phenolphthalein indicator.

Gluconolactone, an intermediate in the metabolic pathway, was measured by the hydroxamate method of Lipmann and Tuttle ${ }^{20}$ and Hestrin, ${ }^{14}$ as modified by Lien. ${ }^{19}$ Samples were removed from the fermentor with a syringe. As discussed by Humphrey and Reilly, ${ }^{16}$ this substance will accumulate in the fermentation broth in the absence of a lactonase, especially at low $\mathrm{pH}$. The lactone hydrolyzes spontaneously to gluconic acid.

A pseudo-steady state was defined by three variables: (1) a constant dissolved oxygen activity; (2) a constant rate of acid production; and $(3)$ a constant bulk concentration of gluconolactone. Steady state was usually attained in about $2 \mathrm{hr}$.

After a pseudo-steady state had been established, the rate of oxygen utilization was measured by noting the rate of depletion of dissolved oxygen with the air supply cut off. The agitation rate was lowered to $120 \mathrm{RPM}$ during these measurements to minimize surface reaeration. A small correction factor was nevertheless applied to compensate for this effect.

For runs in which fermentation rates were measured as a function of $\mathrm{pH}$, the $\mathrm{pH}$ was altered by rapid addition of either $10 \mathrm{~N}$ sulfuric acid or $4 \mathrm{~N}$ sodium hydroxide.

\section{RESULTS}

The effect of agitation on the gluconic acid production rate at pseudo-steady state is shown in Figure 1. In this experiment, the dissolved oxygen level varied from $46 \%$ of saturation at $255 \mathrm{RPM}$ to $93 \%$ at 515 RPM. These values are well above the critical level of $16 \%$ determined by Bennett. ${ }^{4}$

Four main points should be noted. First, the rate of oxygen absorption increased with increasing agitation, even though the dissolved oxygen level was well above the critical. The steady state acid production rate and lactone concentration, the acid production rate after aeration was stopped, and the oxygen consumption rate BIOTECHNOLOGY AND BIOENGINEERING, VOL. XII, ISSUE 2 


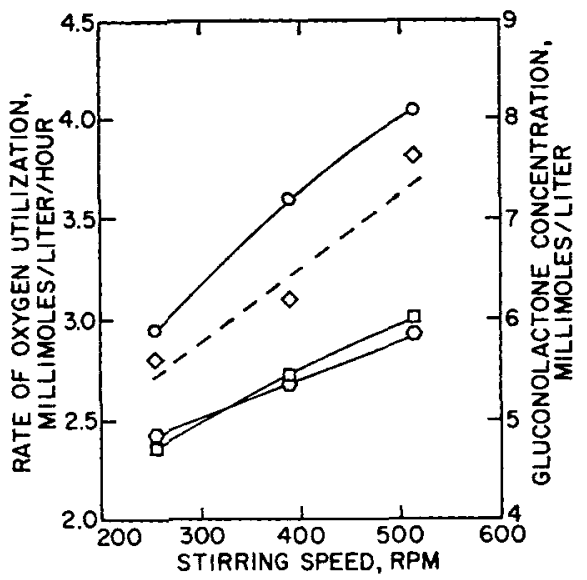

Fig. 1. The effect of the agitation rate on the rate of oxygen utilization and the gluconolactone concentration in the gluconic acid fermentation by resting cells of Pseudomonas ovalis in 2 liters of Medium B at $\mathrm{pH} 7.0,25^{\circ} \mathrm{C}$, an aeration rate of 1.0 VVM, and cell concentration of 100 Klett units. Key: ( $\square$ ) Oxygen uptake rate measured by acid production with aeration; $(\diamond)$ oxygen uptake rate measured by acid production just after aeration was stopped; $(\bigcirc)$ oxygen uptake rate measured by dissolved oxygen depletion with stopped aeration; (O) steady state lactone concentration.

measured by oxygen depletion with stopped aeration, all increased with increased agitation.

Second, at any given agitation rate the curves of dissolved oxygen versus time after the air was cut off, corrected for surface aeration, were more or less linear, above about $25 \%$ of saturation. The slopes of the curves were dependent on the agitation rate just prior to cutting off the air.

Third, the rate of oxygen consumption measured by steady state acid production and the rate measured by oxygen depletion with stopped aeration were nearly the same.

Fourth, the rate of acid production just after aeration was stopped was considerably higher then the steady state and transient rates of oxygen consumption. The lactone concentration fell less than ten percent during this interval.

The effects of $\mathrm{pH}$ on the acid production rate and the gluconolactone concentration are shown in Figure 2. The rate of acid production was a maximum at $\mathrm{pH}$ 7.3. The lactone concentrations were rela- 

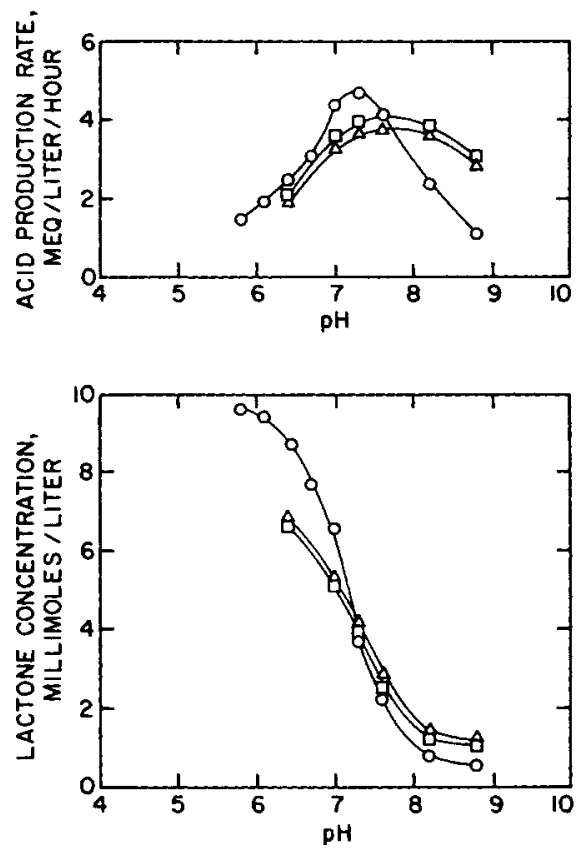

Fig. 2. The effect of $\mathrm{pH}$ on the rate of gluconic acid production and the lactone concentration in the gluconic acid fermentation by resting cells of Pseudomonas ovalis in 2 liters of Medium $B$ at $25^{\circ} \mathrm{C}, 315 \mathrm{RPM}, 1.0 \mathrm{VVM}$, and Klett reading 100. Key: (O), Run I, 16 hour culture; $(\square)$, Run II, and $(\Delta)$, Run III, 20 hour cultures.

tively high at lower $\mathrm{pH}$ values, falling to rather low values as the $\mathrm{pH}$ was increased. The curve is more or less sigmoid, and the inflection point is near the $\mathrm{pH}$ at which acid production was maximal.

An experiment was performed to determine the transient response of the system to a step change in $\mathrm{pH}$. A pseudo-steady state was established at $\mathrm{pH} 7.0$; then the $\mathrm{pH}$ was quickly changed to 6.7 . After a new steady state was established, the $\mathrm{pH}$ was abruptly changed back to 7.0 .

The results are presented in Figure 3 . When the $\mathrm{pH}$ was changed to 6.7 there was an immediate drop in acid production, followed by a slower recovery to a new steady value, lower than the value previously established at $\mathrm{pH}$ 7.0. The lactone concentration rose slowly, the BIOTECHNOLOGY AND BIOENGINEERING, VOL. XII, ISSUE 2 


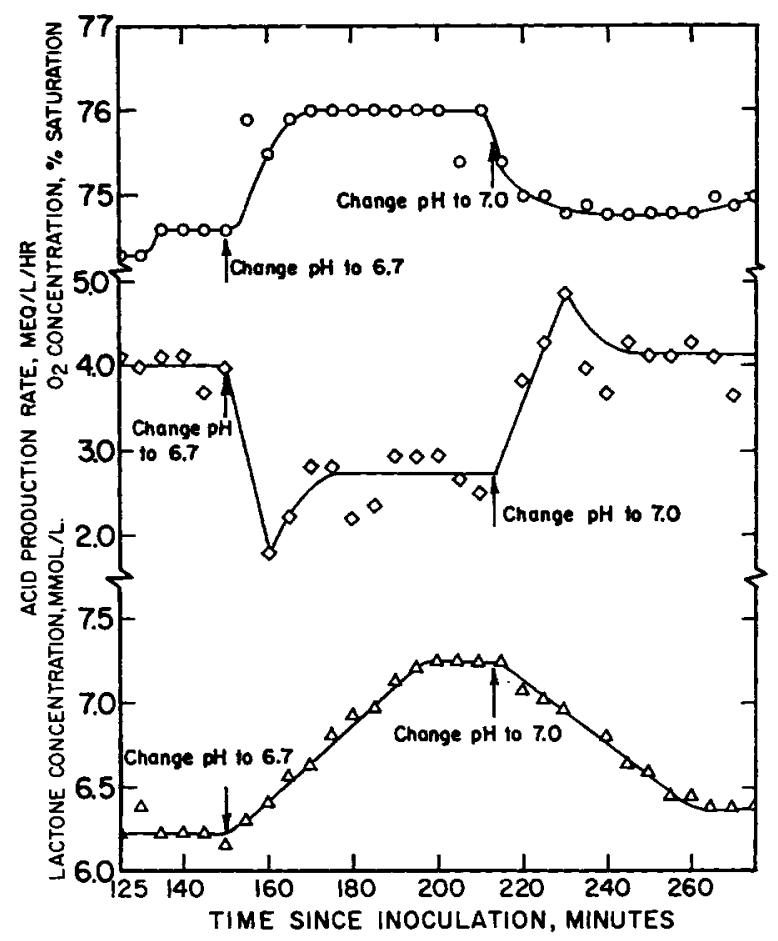

Fig. 3. Response of resting cells of Pseudomonas ovalis in the gluconic acid fermentation to a step change in $\mathrm{pH}$. Liquid volume, 2 liters; aeration rate, 1.0 VVM; agitation rate, $315 \mathrm{RPM}$; temperature, $25^{\circ} \mathrm{C}$; cell concentration, 100 Klett units, initial $\mathrm{pH}, 7.0$.

change being apparently linear with respect to time, to a new steady value. Both changes took about $50 \mathrm{~min}$.

The change in dissolved oxygen concentration occurred much more rapidly, requiring about $20 \mathrm{~min}$. This indicates that the bacterial enzyme system responded much more rapidly than did the system as a whole, including non-enzymatic phenomena, such as hydrolysis of the lactone.

When the $\mathrm{pH}$ was re-established at 7.0 , the effects just described were essentially reversed.

Lastly, a series of experiments was designed to see whether the magnitude of the gas-liquid interfacial area has any effect on the chemistry of the fermentation in the absence of oxygen absorption. 
In these runs, the rate of lactone disappearance under anaerobic conditions was measured. For these experiments, a pseudo-steady state was established, and then aeration and agitation were stopped until essentially all air bubbles had disappeared. Nitrogen gas was either sparged through the broth, or was passed through the head space of the fermentor. Agitation was resumed, and the lactone concentration and rate of sodium hydroxide addition were measured every four minutes, until the lactone concentration had fallen to about $0.003 \mathrm{M}$.

Determinations of the rate of lactone disappearance and of acid production were made for two cases: (1) with nitrogen passed through the head space of the fermentor, and (2) with nitrogen sparged through the broth at $1.0 \mathrm{VVM}$. These determinations were made for a series of agitation rates.

The rate of disappearance of the lactone could be represented by a first order equation

$$
-d[L] / d t=k[L]
$$

where $[L]$ is the lactone concentration and $k$ is a constant. Typical curves, both with and without nitrogen bubbles, are shown in Figure 4 . The rate of acid formation could also be expressed by a first order equation

$$
d[A] / d t=k[L]
$$

where $[A]$ is the concentration of gluconate ion.

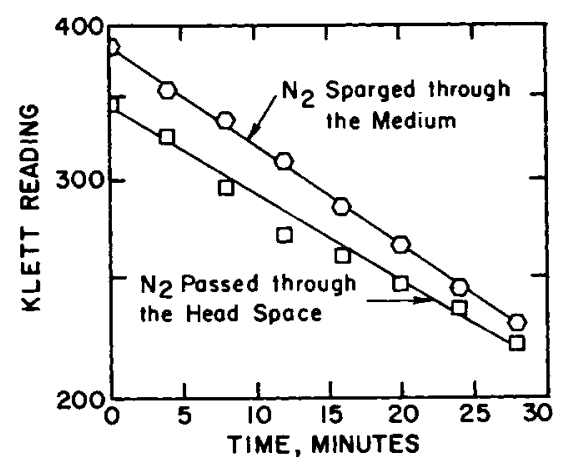

Fig. 4. Rate of disappearance of gluconolactone from a fermentation broth in the gluconic acid fermentation of Pseudomonas ovalis after the air supply has been cut off. Liquid volume, 2 liters; agitation rate, $310 \mathrm{RPM}$; temperature, $25^{\circ} \mathrm{C}$; cell concentration, 100 Klett units. 
It was consistently found that the lactone disappeared faster when nitrogen bubbles were present than when nitrogen was merely passed through the fermentor head space. On the other hand, the kinetic coefficients for acid formation were smaller in the presence of nitrogen bubbles than the coefficients in the absence of bubbles. The coefficients, designated $K_{9}$ for lactone disappearance, and $k_{5}$ for acid formation, are presented in Table I. Thus it appears that the presence of a large interfacial area has a direct effect on the kinetics of the chemical or biochemical reactions of the system.

\section{TABLE I}

Coefficients for the Disappearance of Lactone from Medium B in the Absence of Molecular Oxygen for the Gluconic Acid Fermentation by Resting Cells of Pseudomonas ovalis

(Liquid Volume, 2 Liters; $\mathrm{pH}, 7.0$; Temperature, $25^{\circ} \mathrm{C}$; Cell Concentration, 100 Klett Units. The Coefficients are Defined in the Text)

\begin{tabular}{ccccc}
$\begin{array}{c}\text { Agitation } \\
\text { rate, } \\
\text { RPM }\end{array}$ & $\begin{array}{c}K_{9} \times 10^{2} \\
\text { Nitrogen in } \\
\text { head space } \\
\left(\mathrm{min}^{-1}\right)\end{array}$ & $\begin{array}{c}K_{9}{ }^{\prime} \times 10^{2} \\
\text { Nitrogen } \\
\text { bubbles } \\
\left(\mathrm{min}^{-1}\right)\end{array}$ & $\begin{array}{c}k_{5} \times 10^{2} \\
\text { Nitrogen in } \\
\text { head space } \\
\left(\mathrm{min}^{-1}\right)\end{array}$ & $\begin{array}{c}k_{5}{ }^{\prime} \times 10^{2} \\
\text { Nitrogen } \\
\text { bubbles } \\
\left(\mathrm{min}^{-1}\right)\end{array}$ \\
\hline 205 & 1.73 & 1.74 & 1.14 & 1.12 \\
253 & 1.61 & 1.78 & 1.01 & 0.92 \\
255 & 1.67 & 1.79 & 1.03 & 1.01 \\
273 & 1.60 & 1.75 & 0.92 & 0.95 \\
273 & 1.83 & 2.00 & 1.11 & 1.02 \\
273 & 1.87 & 1.93 & 1.19 & 0.98 \\
310 & 1.60 & 1.87 & 1.11 & 1.01 \\
311 & 1.53 & 1.67 & 0.97 & 0.81 \\
345 & 1.59 & 1.86 & 1.09 & 0.90 \\
345 & - & 1.83 & - & 1.05 \\
\hline
\end{tabular}

Finally, the kinetic constants for acid formation are smaller than the corresponding constants for lactone disappearance. This indicates that not all of the lactone originally present in the broth when the air supply was cut off was hydrolyzed to gluconic acid.

\section{DISCUSSION}

It has been shown that the steady state rate of gluconic acid production by resting cells of $P$. ovalis could be increased by increasing the agitation rate. This was true even when the dissolved oxygen level was above the "critical." Furthermore, the concentration of 
gluconolactone also increased. As shown above, such an increase cannot be attributed to an increase in the oxygen transfer coefficient. The increase must be due to an effect of the gas-liquid interfacial area on the kinetics of enzyme action in the formation of lactone. Phenomenologically, then, the rate of the gluconic acid fermentation is determined by the net rate of lactone formation.

The formation of gluconate from glucose by Pseudomonas $s p$. is somewhat unusual, in that it does not require phosphorylation of the glucose. ${ }^{17,26}$ The first step in the reaction scheme is dehydrogenation of glucose to form gluconolactone. Eichel and Wainio ${ }^{8}$ found that the complete system for the aerobic oxidation of glucose in mammalian liver required only glucose dehydrogenase, $\mathrm{NAD}^{+}$, cytochrome c, and cytochrome oxidase. Participation of other cytochromes or of flavor proteins could not be detected. Reactions in cytochrome systems are reversible. ${ }^{9,13,22}$ Reversibility of the lactone formation reaction has also been demonstrated. ${ }^{26}$ Thus, the entire reaction sequence up to the lactone hydrolysis step can be considered as reversible, and proceeds according to the scheme:

$$
\begin{gathered}
\beta \text {-D-glucopyranose }+\mathrm{NAD}+\rightleftharpoons \text { D-glucono- } \delta \text {-lactone }+\mathrm{NADH}+\mathrm{H}^{+} \\
\mathrm{NADH}+\mathrm{H}^{+}+2 \text { cyt } \mathrm{c}\left(\mathrm{Fe}^{+3}\right) \rightleftharpoons \mathrm{NAD}^{+}+2 \mathrm{cyt} \mathrm{c}\left(\mathrm{Fe}^{+2}\right)+2 \mathrm{H}^{+} \\
2 \mathrm{cyt} \mathrm{c}\left(\mathrm{Fe}^{+2}\right)+2 \text { cyt } \mathrm{a}_{3}\left(\mathrm{Fe}^{+3}\right) \rightleftharpoons 2 \text { cyt } \mathrm{c}\left(\mathrm{Fe}^{+3}\right)+2 \mathrm{cyt} \mathrm{a}_{3}\left(\mathrm{Fe}^{+2}\right) \\
2 \mathrm{cyt} \mathrm{a}_{3}\left(\mathrm{Fe}^{+2}\right)+\frac{1}{2} \mathrm{O}_{2}+2 \mathrm{H}^{+} \rightleftharpoons 2 \text { cyt } \mathrm{a}_{3}\left(\mathrm{Fe}^{+3}\right)+\mathrm{H}_{2} \mathrm{O} \\
\text { D-glucono- } \delta \text {-lactone }+\mathrm{H}_{2} \mathrm{O} \rightarrow \text { D-gluconic acid }
\end{gathered}
$$

Overall:

$$
\text { D-glucose }+\frac{1}{2} \mathrm{O}_{2} \rightarrow \text { D-gluconic acid }
$$

The reversibility of cytochrome systems is controlled by the ATP/ADP $+P_{i}$ ratios in, e.g., mitochondria. Phosphorylation, however, is not involved in the gluconic acid fermentation step of glucose metabolism by $P$. ovalis. Experiments by the authors with the uncoupling agent 2,4-dinitrophenol showed no effect of this substance at concentrations up to $100 \mathrm{ppm}$. The reversibility of the $P$. ovalis cytochrome systems in the gluconic acid fermentation depends only on the equilibrium constant for the system. One function of eytochrome systems is to provide for the transport of electrons in steps involving small changes of redox potential. The standard redox changes are about $0.3 \mathrm{~V}$. Thus, at unit activity these systems are nearly irreversible. However, the components of the system at BIOTECHNOLOGY AND BIOENGINEERING, VOL. XII, ISSUE 2 
hand are not at unit activity. In fact, the components are ordinarily quite far from unit activity. For a standard free energy change of 5000 to $15,000 \mathrm{cal} / \mathrm{mol}$, corresponding to a standard redox potential of approximately $0.3 \mathrm{~V}$, reversal of the system under nonstandard conditions is entirely feasible from a thermodynamic viewpoint.

The cytochromes and $\mathrm{NAD}^{+}$function as electron and proton carriers. If it is assumed that formation of an enzyme-sugar complex is the controlling reaction, then the following highly simplified reaction scheme can be proposed for the conversion of glucose to gluconic acid ty $P$. ovalis.

$$
\begin{gathered}
E+S \underset{k_{2}}{\stackrel{k_{1}}{\rightleftharpoons}} E S \\
E S+\frac{1}{2} \mathrm{O}_{2} \underset{k_{4}}{\stackrel{k_{3}}{\rightleftharpoons}} E+L+W \\
L+W \stackrel{k_{s}}{\longrightarrow} A
\end{gathered}
$$

$E$ is the free enzyme, $S$ is sugar, $E S$ is an activated enzyme-sugar complex, $\mathrm{O}_{2}$ is oxygen, $L$ is the gluconolactone, $W$ is water, and $A$ is the product, gluconic acid.

Assuming the concentration of the enzyme-sugar complex is constant in the pseudo-steady state, then

$$
d[E S] / d t=0=k_{1}[E][S]-\left(k_{2}+k_{3}\left[O_{2}\right]^{1 / 2}\right)[E S]+k_{4}[E][L][W]
$$

For resting cells the total enzyme concentration is a constant:

$$
[E]_{0}=[E]+[E S]
$$

Solving for $[E S]$ and $[E]$ in terms of $[E]_{0}$ :

$$
\begin{aligned}
{[E] } & =\frac{k_{2}+k_{3}\left[\mathrm{O}_{2}\right]^{1 / 2}}{k_{1}[S]+k_{2}+k_{3}\left[\mathrm{O}_{2}\right]^{1 / 2}+k_{4}[L][W]}[E]_{0} \\
{[E S] } & =\frac{k_{1}[S]+k_{4}[L][W]}{k_{1}[S]+k_{2}+k_{3}\left[O_{2}\right]^{1 / 2}+k_{4}[L][W]}[E]_{0}
\end{aligned}
$$

Under pseudo -steady state conditions $d[L] / d t$ is zero. If it is assumed that $[L]^{2} \ll[L]$, and that $[W]$ can be replaced with activity units, with $a_{W}=1$, then

$$
[L]=\frac{k_{1} k_{3}[E]_{0}}{\frac{k_{2} k_{4}[E]_{0}}{[S]\left[\mathrm{O}_{2}\right]^{1 / 2}}+\frac{k_{1} k_{5}}{\left[O_{2}\right]^{1 / 2}}+\frac{k_{2} k_{5}}{[S]\left[\mathrm{O}_{2}\right]^{1 / 2}}+\frac{k_{3} k_{5}}{[S]}}
$$


If sugar is present in large excess, so that $[S]$ is constant, then

$$
[L]=\frac{K_{3}}{\left(K_{1} /\left[\mathrm{O}_{2}\right]^{1 / 2}\right)+K_{2}}=\frac{K_{3}\left[\mathrm{O}_{2}\right]^{1 / 2}}{K_{1}+K_{2}\left[\mathrm{O}_{2}\right]^{1 / 2}}
$$

The rate of product formation is thus

$$
d[A] / d t=k_{5}[L][W]=k_{5}[L]=\frac{K_{4}\left[\mathrm{O}_{2}\right]^{1 / 2}}{K_{1}+K_{2}\left[\mathrm{O}_{2}\right]^{1 / 2}}
$$

If $K_{2}\left[\mathrm{O}_{2}\right]^{1 / 2} \gg K_{1}$ then

$$
d[A] / d t=K_{4} / K_{2}=K_{5}=k_{1}[E]_{0}[S]=k_{5}[L]
$$

since $K_{4}=k_{5} K_{3}=k_{1} k_{3} k_{5}[E]_{0}$ and $K_{2}=k_{3} k_{5} /[S]$.

Equation (15) predicts that if $K_{2}$ is large then the rate of acid production will be independent of the dissolved oxygen concentration above a value characteristic of the kinetic constants of the enzyme system. This concentration may be identified with the classical "critical" oxygen concentration.

Equation (16) predicts that the controlling reaction when the dissolved oxygen concentration is above the "critical" will be the rate of formation of the activated enzyme-glucose complex.

For the anaerobic disappearance of lactone, the following reactions remain:

$$
\begin{gathered}
E+L+W \stackrel{k_{4}}{\rightarrow} E S+\frac{1}{2} \mathrm{O}_{2} \\
E S \underset{k_{1}}{\stackrel{k_{2}}{\rightleftharpoons}} E+S \\
L+W \stackrel{k_{5}}{\rightarrow} A
\end{gathered}
$$

The assumption has been made that oxygen molecules are stripped away by the nitrogen as soon as they are produced. If one component is completely removed from the reaction pathway in this manner, then according to the law of mass action, the reactions will tend to proceed so as to restore that component. Thus, under anaerobic conditions $P$. ovalis should be capable of producing glucose and oxygen from gluconolactone and water. Proceeding in a fashion similar to the above, we arrive at

$$
-\frac{d[L]}{d t}=\frac{K_{6}[L]}{K_{7}+k_{4}[L]}+k_{5}[L]
$$

BIOTECHNOLOGY AND BIOENGINEERING, VOL. XII, ISSUE 2 
If $K_{7} \gg k_{4}[L]$

$$
-(d[L] / d t)=K_{8}[L]+k_{5}[L]=K_{9}[L]
$$

The rate of acid production is simply

$$
d[A] / d t=k_{5}[L]
$$

Equations (18) and (19) are of the same form as eqs. (7) and (8), which agree with the experimental data in form.

The above is consistent with the form of the experimental results, but does not explain the increase in the acid production rate brought about by increased agitation. Since oxygen transfer is not limiting, the effect would have to be due to an increase in the enzymatic reaction rates. Experiments reported here suggest that the surfaces of the bubbles somehow effect an increased reaction rate over that observed in the bulk solution. One such effect will be discussed here. Bacteria possess a negative charge at $\mathrm{pH}$ values above the isoelectric point. When such cells are at a gas-liquid interface, the gas phase acts as an insulator, and large potential gradients are set up in the liquid. The net effect is to attract hydrogen ions to the interface, thus lowering the $\mathrm{pH}$. Quantitatively, the changes are expressed by ?

$$
\left[\mathrm{H}^{+}\right]^{\sigma}=\left[\mathrm{H}^{+}\right]^{\mathrm{b}} \exp (-\epsilon \boldsymbol{\psi} / k t)
$$

The superscript ${ }^{\circ}$ refers to conditions in the surface phase, and $b$ refers to the bulk phase. The electronic charge is $\epsilon$, and $\psi$ is the potential due to the charged particles at the interface. If the net charge on the particles is negative, the $\mathrm{pH}$ in the surface phase will be lower than the $\mathrm{pH}$ in the bulk phase. The effect will be enhanced if there is a high concentration of bacteria at the surface relative to the bulk liquid. Bennett and Kempe ${ }^{5}$ demonstrated such adsorption of $P$. ovalis cells on gas bubble surfaces. Bull ${ }^{6}$ has reported a Gibbs adsorption isotherm for this organism.

The rate of hydrolysis of the lactone decreases as the $\mathrm{pH}$ is lowered. ${ }^{17}$ Since the $\mathrm{pH}$ in the surface film will be lower than in the bulk liquid, lactone hydrolysis is not responsible for the accelerated fermentation rate in the presence of bubbles. However, the controlling factor in the fermentation is the net rate of formation of lactone. This must therefore be increased in the surface film in order for the rate of gluconic acid production to rise. Such an increase would cause an 
increase in the concentration of gluconolactone during the steady state. This was observed experimentally.

The net rate of lactone formation can be expressed as the rate of change of lactone concentration plus the rate of formation of gluconate ion:

$$
\left.\frac{d[L]}{d t}\right|_{\text {Net }}=\frac{d[L]}{d t}+\frac{d[A]}{d t}
$$

In the steady state $d[L] / d t$ is zero. However, if a fluid element is incorporated into the gas-liquid interfacial film, it will be subjected to a decreased $\mathrm{pH}$. The experiment reported here wherein a fermentation was subjected to a step change in $\mathrm{pH}$ might be expected to approximate on a larger scale the situation which is obtained in the surface film. In this experiment, the steady state net rate of lactone formation, equal to the rate of acid production, was $3.96 \mathrm{meq} / \mathrm{l} / \mathrm{hr}$. The net rate of lactone formation just after the $\mathrm{pH}$ was lowered, equal to the sum of the rate of change of lactone concentration and the rate of acid production, was $4.28 \mathrm{meq} / \mathrm{l} / \mathrm{hr}$. It is plausible that a similar transient increase in lactone production rate occurs in the liquid film around gas bubbles in the fermentor. When fluid elements leave the interface, they will contribute to a raising of the lactone concentration in the bulk fluid. At the same time, the $\mathrm{pH}$ of the element will be returned to the higher bulk value, at which the lactone hydrolysis rate constant is higher. The overall effect is an increase in the rate of production of gluconic acid when the interfacial area is increased.

This study was aided by National Science Foundation Grant No. GP-1007.

\section{NOMENCLATURE}

a Gas-liquid interfacial area per unit volume of liquid

$a_{W} \quad$ Activity of water

[A] Concentration of gluconate

$C \quad$ Dissolved oxygen concentration

$C_{s} \quad$ Dissolved oxygen concentration at saturation

$C_{e} \quad$ Dissolved oxygen concentration at chemical equilibrium

$D_{L} \quad$ Diffusivity of oxygen in the fermentation medium

[E] Concentration of free enzyme

$[E]_{0} \quad$ Total enzyme concentration, equal to $[E]+[E S]$

$[E S] \quad$ Concentration of enzyme-glucose complex BIOTECHNOLOGY AND BIOENGINEERING, VOL. XII, ISSUE 2 


$\begin{array}{ll}k_{1}, \ldots k_{5} & \begin{array}{l}\text { Kinetic rate constants in the reaction model for the production of } \\ \text { gluconic acid }\end{array} \\ k_{5} & \begin{array}{l}\text { First order rate constant for acid production with nitrogen passed } \\ \text { through the head space of the fermentor }\end{array} \\ k_{5}{ }^{\prime} & \begin{array}{l}\text { First order rate constant for acid production with nitrogen sparged } \\ \text { through the fermentation medium }\end{array} \\ k_{L} & \begin{array}{l}\text { Coefficient for absorption of oxygen with chemical reaction } \\ \text { Coefficient for physical absorption of oxygen }\end{array} \\ k_{L^{0}} & \begin{array}{l}\text { Specific oxygen transfer coefficient for physical absorption } \\ k_{L^{0} a}\end{array} \\ K_{1}, \ldots, K_{9}, \begin{array}{l}\text { Lumped kinetic coefficients in the reaction model for the produc- } \\ \text { tion of gluconic acid }\end{array} \\ K_{9} & \begin{array}{l}\text { First order rate coefficient for the disappearance of lactone with } \\ \text { nitrogen passed through the head space of the fermentor }\end{array} \\ K_{9}^{\prime} & \begin{array}{l}\text { First order rate coefficient for the disappearance of lactone with } \\ \text { nitrogen sparged through the fermentation medium }\end{array} \\ {[L]} & \text { Concentration of gluconolactone } \\ {\left[\mathrm{O}_{2}\right]} & \text { Dissolved oxygen concentration } \\ q & \text { Instantaneous oxygen absorption rate } \\ r & \text { Volumetric rate of oxygen consumption by the cells } \\ {[S]} & \text { Concentration of glucose } \\ t_{D} & \text { Equivalent diffusion time, defined in eq. (16) } \\ t_{r} & \text { Reaction time, defined in eq. (17) } \\ T & \text { Absolute temperature } \\ {[W]} & \text { "Concentration" of water, assumed equal to } a_{W} \\ \epsilon & \text { Electronic charge in e.s.u. } \\ \psi & \text { Electrostatic potential at the gas-liquid interface due to a net }\end{array}$

\section{References}

1. S. Aiba, M. Hara, and J. Someya, J. Gen. Appl. Microbiol., 9, 163 (1963).

2. Giovanni Astarita, Mass Transfer with Chemical Reaction, Elsevier Pub. Co., Amsterdam, 1967.

3. W. H. Bartholomew, E. O. Karow, M. R. Sfat, and R. H. Wilhelm, Ind. Eng. Chem., 42, 1801 (1950).

4. G. F. Bennett, Ph. D. Thesis, University of Michigan, Ann Arbor, 1963.

5. G. F. Bennett and L. L. Kempe, Biotechnol. Bioeng., 6, 347-360 (1964).

6. D. N. Bull, Ph. D. Thesis, University of Michigan, Ann Arbor, 1968.

7. J. T. Davies and E. K. Rideal, Interfacial Phenomena, Academic Press, New York, 1961.

8. B. Eichel and W. W. Wainio, J. Biol. Chem., 175, 155 (1948).

9. L. Ernster and C. P. Lee, Ann. Rev. Biochem., 33, 729 (1964).

10. J. M. Fife, J. Agr. Research, 66, 421-440 (1943).

11. E. L. Gaden, Jr., Sci. Repts. Ist. Super. Sanita, 1, 161 (1961).

12. M. J. Goodkind and E. N. Harvey, J. Cell. Comp. Physiol., 39, 45-56 (1952).

13. D. E. Griffiths, in Essays in Biochemistry, P. N. Campbell and G. D. Greville (eds.), Biochemical Society/Academic Press, New York, 1965. 
14. S. Hestrin, J. Biol. Chem., 180, 249 (1949).

15. D. P. H. Hsieh, R. S. Silver, and R. I. Mateles, Biotechnol. Bioeng., 11, 1 (1969).

16. A. E. Humphrey and P. J. Reilly, Biotechnol. Bioeng., 7, 229-243 (1965).

17. M. A. Jermyn, Biochim. Biophys. Acta, 37, 78 (1960).

18. W. Kempner, J. Cell. Comp. Physiol., 10, 339-363 (1937).

19. O. G. Lien, Jr., Anal. Chem., 31, 1363 (1959).

20. F. Lipmann and L. C. Tuttle, J. Biol. Chem., 159, 21 (1945).

21. L. B. Lockwood, B. Tabenkin, and G. E. Ward, J. Bact., 42, 51 (1941).

22. V. Massey and C. Veeger, Ann. Rev. Biochem., 32, 579 (1963).

23. K. L. Phillips, H. R. Sallans, and J. F. T. Spencer, Ind. Eng. Chem., 53, 749 (1961).

24. G. W. Rolinson, J. Gen. Microbiol., 6, 336 (1952).

25. S. D. Siegell and E. L. Gaden, Jr., Biotechnol. Bioeng., 4, 345 (1962).

26. H. J. Strecker and S. Korkes, J. Biol. Chem., 196, 769 (1952).

27. J. A. Strohm, R. F. Dale, and H. J. Peppler, Appl. Microbiol., 7, 235 (1959).

28. R. P. Tengerdy, J. Biochem. Microbiol. Tech. and Eng., 3, 241 (1961).

29. G. T. Tsao, Biotechnol. Bioeng., 10, 765 (1968).

30. G. T. N. Tsao and L. L. Kempe, J. Biochem. Microbiol. Tech. and Eng., 2, 129 (1960).

31. J. M. West and E. L. Gaden, Jr., J. Biochem. Microbiol. Tech. and Eng., 1, 163-172 (1959).

32. R. J. Winzler, J. Cell. Comp. Physiol., 17, 263 (1941).

Received January 2, 1970 